\title{
Effects of salinity on the larval development of a semiterrestrial tropical crab, Sesarma angustipes (Decapoda: Grapsidae)
}

\author{
K. Anger ${ }^{1}$, J. Harms ${ }^{1}$, M. Montú ${ }^{2}$, C. de Bakker ${ }^{2}$ \\ ' Biologische Anstalt Helgoland, Meeresstation, D-2192 Helgoland, Federal Republic of Germany \\ ${ }^{2}$ Centro de Biologia Marinha, Universidade Federal do Paraná, 83200 Pontal do Sul, PR, Brazil
}

\begin{abstract}
Hatching and larval development of the semiterrestrial tropical brachyuran Sesarma angustipes were studied in relation to salinity in laboratory experiments. Adults were found in southern Brazil living in terrestrial habitats and in freshwater creeks. When a free choice was offered in the laboratory, females liberated their larvae indiscriminately in freshwater or seawater Rearing experiments were carried out at $0,3,10,20$, and $32 \%$ S. Unlike in other marine and brackish water species, freshly hatched zoea I larvae remained actively swimming in freshwater, where they survived for almost. $2 \mathrm{~d}$. Maximum survival time of zoea I exposed to $3 \% \mathrm{~S}$ was ca $3.5 \mathrm{~d}$. The larvae were able to pass through some or all developmental instars ( 4 zoeal stages and 1 megalopa) only at higher salinities. The zoea I at all salinities $\geq 10 \% \mathrm{~S}$ had a high survival rate to the second stage. Its minimum duration of development (with $100 \%$ survival), however, was observed at $20 \%$ S. From the zoea II stage, survival was in general highest and development shortest at $32 \% \mathrm{~S}$, whilst $10 \%$ S allowed only occasional development to later stages. This indicates a decreasing tolerance to low salinities and a shift in optimum salinity toward seawater in successive zoeal instars. Only 2 megalopae successfully reached metamorphosis to the juvenile crab, both at $20 \% \mathrm{~S}$. These results may reflect the following hypothetical patterns in larval development of $S$. angustipes under field conditions: (1) the zoea I may hatch in freshwater or brackish water; (2) if hatching takes place in freshwater, the larva has 1 to $2 \mathrm{~d}$ to be transported by currents to brackish water or seawater; (3) the major part of zoeal development (from the zoea II or III stage) takes place in lower estuaries and coastal oceanic waters with $>20 \% S_{;}(4)$ the megalopa may return to less saline environments. It remains unknown whether the megalopa can successfully metamorphose in freshwater, or if recruitment in rivers and other freshwater biota takes place by upstream migration of juveniles. Our results show that $S$. angustipes must be considered a marine species that has only started its transition to terrestrial and freshwater habitats. Larval morphology of $S$. angustipes was practically identical with that presented in a previous description of Sesarma ricordi larvae, confirming the hypothesis that these 2 species are synonyms.
\end{abstract}

\section{INTRODUCTION}

The transition from life in the marine environment to terrestrial and freshwater habitats has been achieved by many brachyuran crab species, in particular members of the families Gecarcinidae, Ocypodidae, Hymenosomatidae, and Grapsidae (Burggren \& McMahon 1988). While most of these species need to return to the sea in order to reproduce, others show abbreviated or absent larval development as an adaptation to their life on land or in freshwater (Lucas 1980, Powers \& Bliss 1983, Rabalais \& Gore 1985). Within the Grapsidae, the mangrove tree crab Aratus pisoni Milne Edwards, the Chinese mitten crab Eriocheir sinensis
Milne Edwards, and a number of Sesarma species belong to the best-known examples of such transitions. The latter genus is particularly interesting, as it comprises marine and brackish water species which have 3 or 4 zoeal stages, as well as freshwater and semiterrestrial species with only 2 stages (Rabalais \& Gore 1985). Abbreviated larval development is usually associated with lecithotrophy (Hartnoll 1964, Lam 1969).

Sesarma angustipes Dana, 1852 is often referred to by the synonyms $S$. miersi or $S$. ricordi (for taxonomy of this species see Abele 1972a). It is one of those species that can live in marine, terrestrial and freshwater habitats. It occurs on islands in the Carribean Sea (Hartnoll 1965) and along the tropical and subtropical 
coasts of Brazil, south to the state of Santa Catarina (Melo 1984). It is often found in the marginal zones of tropical estuarine mangrove swamps (e.g. Gerlach 1958, Melo 1984). Hartnoll (1965) observed it frequently in Jamaican rivers, up to ca $100 \mathrm{~m}$ upstream from their mouths, while some authors also reported it from the freshwater that is collected by bromeliad plants (Sattler \& Sattler 1965, McWilliams 1969, Abele 1972b).

The present authors have observed adult Sesarma angustipes in Pontal do Sul (state of Paraná, Brazil) occurring regularly in dry terrestrial habitats near a mangrove river (also inside the Centro de Biologia Marinha [CBM] laboratory building), without any tendency to flee toward open water. Moreover, we found them on the nearby island Ilha do Mel (Paraná) and near São Sebastião (state of São Paulo), living on rocks in mountain creeks that merge in mangrove swamps or disappear in sandy beaches on the open Atlantic coast. We never observed $S$. angustipes on a beach or in seawater.

The type of development in Sesarma angustipes has not yet been ascertained with certainty. Since this species often lives in isolated freshwater habitats, abbreviated or direct development might have been expected, as well as a regular meroplanktonic development through several larval stages. The latter mode of development is more likely, as Abele (1972a) considered $S$. ricordi a synonym of $S$. angustipes, after Díaz \& Ewald (1968) had described 5 zoeal and 1 megalopa stage in $S$. ricordi from Venezuela. Hartnoll (1965) assumed that the zoeae of $S$. angustipes hatch in freshwater and then develop in the sea; however, this assumption remained unconfirmed by experimental evidence. Therefore, we investigated hatching and development of $S$. angustipes larvae under controlled conditions in the laboratory.

\section{MATERIALS AND METHODS}

Male and ovigerous female Sesarma angustipes were collected in November 1988 in and near to a freshwater mountain creek on the marine island of llha do Mel (Paraná, Brazil) and then transferred to the CBM (Pontal do Sul). There they were maintained in a large glass aquarium in which small plastic aquaria $(21 \times 11 \times 3.5 \mathrm{~cm})$ were inserted, with some bottom space left free. The smaller aquaria were filled with either seawater (ca $32 \%$ S) or freshwater. The crabs could move freely on the dry bottom (with stones facilitating climbing), and they could easily enter and leave the small seawater and freshwater aquaria. This experiment was intended to (1) provide information on possible differential habitat preferences in adult males and females, (2) show where the females eventually release their larvae, and (3) yield freshly hatched larvae for rearing experiments.

Freshly hatched zoea larvae were collected with wide-bore pipettes and transferred directly to cultivation vials ( $30 \mathrm{ml}$, for individual rearing) and glass bowls $(400 \mathrm{ml}$, for mass rearing); the latter were used for morphological studies. Salinities tested in individual rearing experiments were: 0 (freshwater, from tap), 3, $10,20 \% \mathrm{~S}$, and ambient coastal seawater (ranging between 29 and $33 \%$ S, but mostly near $32 \%$ S). Both freshwater and seawater were filtered prior to use or mixing. In each salinity, 50 sibling larvae (originating from the same female) were used. The experiments were carried out at a constant $25( \pm 1)^{\circ} \mathrm{C}$ and a $12: 12 \mathrm{~h}$ L: D light regime. Water and food (freshly hatched San Francisco Bay Brand ${ }^{\mathrm{TM}}$ Artemia sp. nauplii) were changed daily. During the first $4 \mathrm{~d}$, the cultures were checked every $12 \mathrm{~h}$ for mortality and moults, thereafter only every 24 h (during a water change).

Morphological studies were carried out with fixed material (both larvae and exuviae stored in $4 \%$ formaldehyde in seawater) that was later dissected under a Wild stereo microscope and examined under a Leitz compound microscope. Thirty individuals were checked in each of the zoeal stages and 10 in the megalopa. Statistical comparison of mean values with equal or unequal variances (after an F-test) was carried out using different t-statistics (Sachs 1984)

\section{RESULTS}

\section{Habitat selection experiment}

During ca 2 wk of daily observation, no clear habitat selection was exhibited by either males or females. Most individuals remained outside the water, but both freshwater and seawater also were entered indiscriminately.

Hatching of larvae took place in both types of water, with a slight preponderance in freshwater. A few hours after hatching, the larvae released in freshwater or seawater showed no differences in level of activity. Positive phototaxis and shadow response (Forward 1977) were equally strong in both groups

In no case was moulting, mating, or egg-laying observed after the release of a hatch.

\section{Larval development and morphology}

Under optimum conditions, larvae developed through 4 zoeal stages and a megalopa to the first juvenile crab. Salinity had strong effects on survival rate and, to a lesser degree, on duration of develop- 
ment (see below), but not on the number or morphology of larval instars. Larval morphology was examined and compared with the descriptions given by Díaz \& Ewald (1968) for Sesarma ricordi from Venezuela. A few details in the setation of appendages and the telson were found to differ slightly in some individuals, whereas most larvae corresponded in all details with Díaz \& Ewald's descriptions. Variation was observed mainly in the first maxilliped of the zoea III, where setation formulae of 2 , $3,1,2,5$ and $0,2,2,3,2$ occurred, besides that reported by Diaz \& Ewald $(2,2,2,2,6)$. In the telson of the megalopa, sometimes a central seta occurred on the posterior margin, in addition to 3 short setae on each side and 2 small lateral setae or spines. These deviations were considered taxonomically irrelevant, as they were within the range of individual variability. Our material may thus be considered taxonomically identical with that described by Diaz \& Ewald.

\section{Effects of salinity on larval survival and duration of development}

Freshly hatched larvae were quite active and appeared viable in any salinity, from 0 to $32 \%$ S. However, first mortality was found in freshwater after $12 \mathrm{~h}$ exposure (Fig. 1). Most larvae in this experimental group died within the following $24 \mathrm{~h}$, with complete mortality within 48 h. Larvae maintained at $3 \%$ S survived significantly longer, with $100 \%$ survival during the first $60 \mathrm{~h}$. Thereafter, mortality increased drastically, and the last larvae died within the following $36 \mathrm{~h}$ (Fig. 1).

When first mortality appeared at $3 \% \mathrm{~S}$ (during the third day), one mass culture with this salinity was changed to ca $15 \% \mathrm{~S}$ to save the larval material of this group. Thereafter, mortality in this culture was low during a major part of zoeal development; the initial stress exerted by very low salinity caused no apparent irreversible damage to the larvae.

At $10 \% \mathrm{~S}$, survival was $100 \%$ until the first moult occurred on the third day after hatching (Fig. 1). Of these, $70 \%$ (35 individuals) moulted successfully to the second zoeal stage, and $28 \%$ reached the zoea III instar. Only 2 individuals at this low salinity reached the zoea IV stage, and none the megalopa (Fig. 2).

Survival patterns at 20 and $32 \%$ S were very similar (Fig, 1). Survival at $20 \% \mathrm{~S}$ decreased only after the zoea III instar. At $32 \%$ S all larvae reached the zoea IV. while only $76 \%$ survived at $20 \%$ S (cf. Fig. 2). However, in the megalopa stage there was complete mortality in full seawater (mostly during or shortly after moulting to this stage), whereas 2 individuals (4\%) survived through metamorphosis at $20 \%$ S.

Cumulative survival rates from hatching to succes-
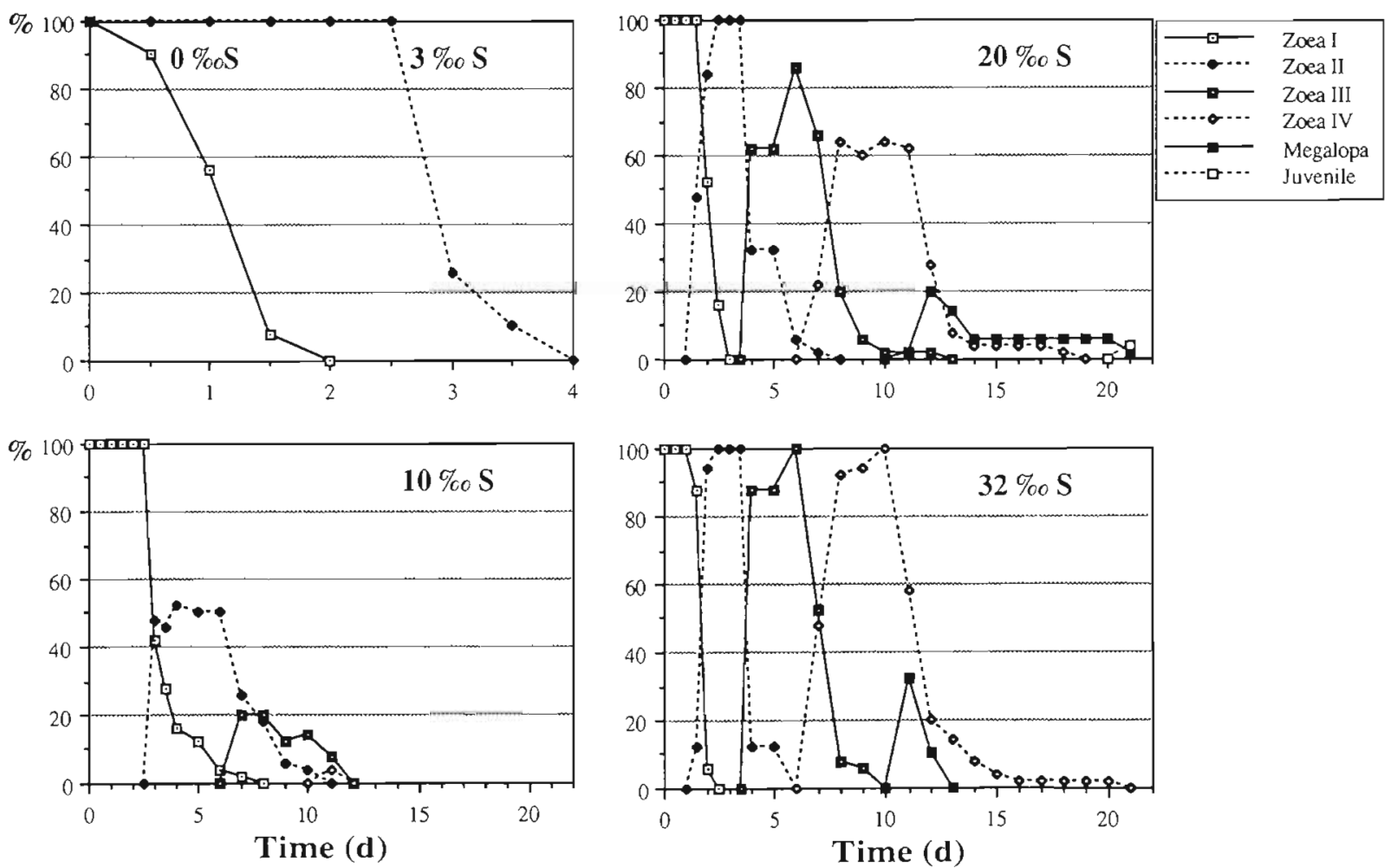

Fig. 1 Sesarma angustipes, larval stages. Survival (\%) and development through successive instars in relation to salinity (\%o S); initial $\mathrm{n}=50$ 

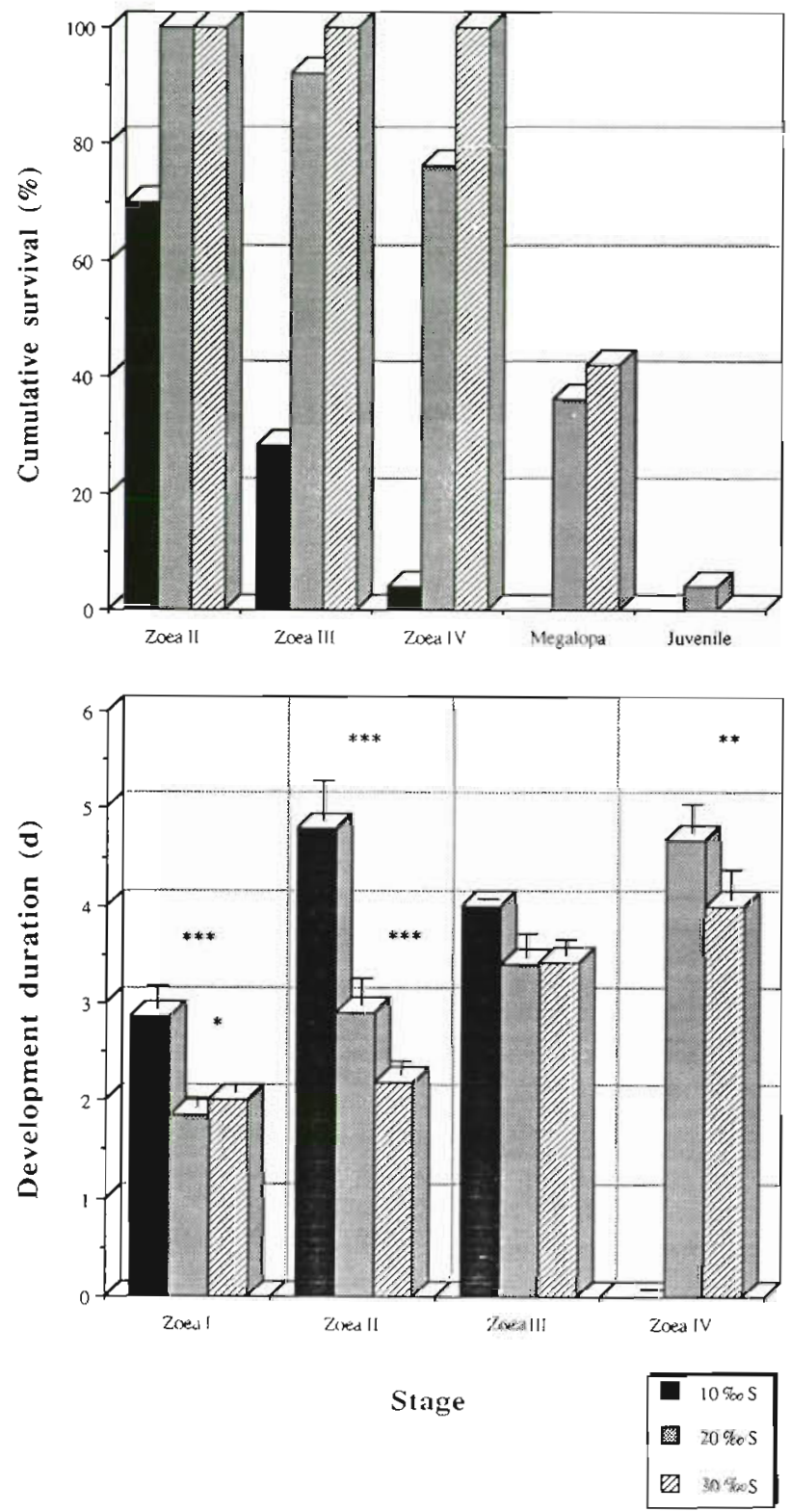

Fig. 2. Sesarma angustipes, larval stages. Cumulative survival rate $(\%)$ from hatching to subsequent instars (upper graph; initial $\mathrm{n}=50)_{\text {; }}$ duration of development $\left(\mathrm{d}_{i} \mathrm{x} \pm 95 \%\right.$ confidence intervals) at 10,20, and ca $32 \%$ S (lower graph), asteriks mark statistically significant differences between mean development times: $p<0.05, \cdots p<0.01, \cdots p<0.001$

sive developmental stages are compared in Fig. 2 (upper graph) for the 3 highest salinities. This comparison shows again that salinities $\leq 10 \%$ S become detremental as soon as the first moult is approached. On the other hand, $20 \% \mathrm{~S}$ resulted in increased mortality (compared with $32 \%$ S) in later zoeal instars, but allowed at least some survival of megalopa larvae through metamorphosis.

Since the larvae were reared individually, duration of development may be calculated separately for each stage. Fig. 2 (lower graph) shows that a strongly reduced salinity (10\% $\quad$ S) increased duration of development significantly. Water of $20 \%$ S in the zoea I instar had a slight but statistically significant $(\mathrm{p}<0.05)$ accelerating effect on duration of development as compared to seawater, whereas later it had no effect (zoea III) or even caused a delay (zoea II, IV).

The patterns shown by these developmental data agree in general with the survival data described above. They may be summarized as follows. (1) Freshly hatched zoea I larvae of Sesarma angustipes may survive in freshwater for 24 to 36 h. (2) At $3 \%$ S the zoeae may survive for more than $3 \mathrm{~d}$, but there is complete mortality when the first moult is approached. (3) $10 \% \mathrm{~S}$ has a significant delaying effect on development, but most zoea I larvae moult successfully to the second stage, a few may reach the third or fourth instar. Later zoeal stages cannot develop in such a low salinity. (4) $20 \%$ S represents a very suitable condition for early larval stages and possibly, again for the ultimate larval instar, the megalopa. (5) Seawater (32\% S) appears optimum for the zoeal stages II to IV, whereas the megalopa did not survive in this condition.

\section{DISCUSSION}

The very close correspondence in larval morphology of Sesarma angustipes from Brazil and S. ricordi from Venezuela (Díaz \& Ewald 1968) provides strong additional support to Abele (1972a) who concluded from comparison of adult specimens that these 2 species were synonyms. The same correspondence should also be expected for $S$. roberti from Africa, since Hartnoll (1965) synonymized it with $S$. angustipes.

The results of the present study confirm Hartnoll's (1965) speculations on the life cycle of Sesarma angustipes. They conform with the view that this species has only begun its transition from marine to freshwater and terrestrial habitats. The adults are very well adapted to tolerate extremely wide variations in salinity and water temperature and to survive long exposure to freshwater or air. The larval stages, in contrast, depend on the existence of aquatic habitats with a higher salinity and enough food organisms to allow planktotrophic development through 5 free-swimming instars. The wide geographical distribution of $S$. angustipes in the South Atlantic likely is due to this regular 'marine' type of larval development.

The first zoeal stage reveals clear adaptations to the species life in freshwater environments. Even in extremely euryhaline brackish-water species, freshly hatched larvae exposed to freshwater will immediately cease swimming and die within a few hours. In con- 
trast, most Sesarma angustipes zoeae remain active and unaffected throughout $1 \mathrm{~d}$, and many individuals may survive even for a second day. This unusual degree of tolerance to osmotic stress would give the zoea I sufficient time to swim actively near the surface and be transported by currents out of their river of origin, into brackish or marine waters.

When the larvae have reached the oligohaline waters of an upper estuary, they would have even more time for their further transport: in a salinity as low as $3 \% \mathrm{~S}$ they can survive about $3 \mathrm{~d}$. This should normally be sufficient for them to reach waters with higher salinities, where longer survival times and some further development become possible. However, it is interesting to note that brackish water conditions with $10 \% \mathrm{~S}$ still have obvious negative effects on larval survival and development rates in Sesarma angustipes, whereas other brackish water species that never live in freshwater (e.g. Rhithropanopeus harrisii) may develop even at $2.5 \% \mathrm{~S}$ (Costlow et al. 1966).

The tolerance of larval Sesarma angustipes to low salinity decreases in successive stages. The zoea I had a quite high survival rate at $10 \% \mathrm{~S}$, and developed equally well at 20 or $32 \% \mathrm{~S}$, with a slightly shorter moult cycle at $20 \%$ S. Although this difference in duration of development is very small ( $1.8 \mathrm{vs} 2.0 \mathrm{~d})$, it is statistically significant ( $p<0.05$; see Fig. 2 ), and it may reflect an adaptation of the zoea I to regular release in freshwater and early development in brackish water habitats.

Later zoeal stages of Sesarma angustipes exhibit a slight preference for fully marine conditions, where they mostly showed shortest development and highest survival rates. At $10 \% \mathrm{~S}$, they revealed clearly delayed development and increased mortality. This shows that $S$. angustipes in its development is still a marine species.

There appears to be a gradual shift from freshwater to seawater in the salinity optimum of successive larval stages, associated with an increasingly stenohaline response. This pattern suggests a possible genetic adaptation to a regularly occurring ontogenetic migration in the life cycle of Sesarma angustipes. A major part of its larval development appears to take place in lower estuaries and in coastal oceanic waters, where salinities between $\mathrm{ca} 20$ and $32 \%$ s are found. This salinity range also was found to be optimal for larval development in other brackish water Sesarma species (e.g. Costlow et al. 1960, Fransozo \& NegreirosFransozo 1986).

The ability for hyperosmotic regulation in very low salinities is in general developed only by late larval or early juvenile stages of decapod crustaceans (Foskett 1977. Charmantier et al. 1981, 1988). Osmoregulation depends on eyestalk factors (Charmantier et al. 1981) that become functional in Sesarma spp. during late zoeal or megalopa development (Costlow 1966). However, the great tolerance to low salinity that is exhibited by the zoea I suggests that this ability may occur much earlier in $S$. angustipes.

The data of the present investigation suggest that the tendency of decreasing tolerance to low salinity with progressive development may be stopped or reversed in the megalopa stage. The only individuals that reached metamorphosis to the first juvenile crab instar were observed at $20 \% \mathrm{~S}$, not in fully marine conditions.

In future experimental studies, larvae of Sesarma angustipes should be reared under optimum (high) salinity conditions to the megalopa stage and then transferred to different conditions of gradually decreasing salinity. Those experimental tests, combined with field collections, should show when developmental stages return from the sea to brackish water and eventually, to freshwater habitats, and where their metamorphosis takes place. Once the complete life cycle of $S$. angustipes is known, this species could become an interesting and suitable model for studies of the ontogeny of osmoregulation in semiterrestrial crabs and hence, a model of the development of physiological adaptations in Crustacea during the transition from life in the sea to freshwater and terrestrial environments.

Acknowledgements. This paper is a result of a cooperative programme between the Centro de Biologia Marinha (CBM) and the Biologische Anstalt Helgoland (BAH) funded by the Comissão Interministerial para os Recursos do Mar (CIRM, Brasilia) and the GKSS Forschungszentrum Geesthacht, on behalf of the German Federal Ministry of Science and Technology (BMfT, Bonn). We also thank the administrations and staffs of the CBM and $\mathrm{BAH}$ for their support and kind cooperation.

\section{LITERATURE CITED}

Abele, L. G. (1972a). The status of Sesarma angustipes, Dana, 1852, S. trapezium Dana, 1852 and S. miersi, Rathbun, 1897 (Crustacea: Decapoda: Grapsidae) in the western Atlantic. Carib. J. Sci. 12: 165-170

Abele, L. G. (1972b). A note on the Brazilian bromeliad crabs (Crustacea, Grapsidae). Arq. Ciên. mar., Fortaleza 12: 123-126

Burggren, W. W., McMahon, B. R. (eds.) (1988). Biology of the land crabs. Cambridge University Press, New York

Charmantier, G., Charmantier-Daures, M., Aiken, D. E. (1981). Contrôle neuroendocrine de la régulation osmotique et ionique chez les juvéniles et les larves de Homarus americanus H. Milne Edwards, 1837. C. r. hebd. Séanc. Acad. Sci., Paris 293: 831-834

Charmantier, G., Charmantier-Daures, M., Bouaricha, N., Thuet, P., Aiken, D. E., Trilles, J.-P. (1988). Ontogeny of osmoregulation and salinity tolerance in two decapod crustaceans: Homarus americanus and Penaeus japonicus. Biol. Bull. mar. biol. Lab., Woods Hole 175: 102-110 
Costlow, J. D. (1966). The effect of eyestalk extirpation on larval development of the crab, Sesarma reticulatum Say. In: Barnes, H. (ed.) Some contemporary studies in marine science. George Allen and Unwin Ltd, London, p. 200-224

Costlow, J. D., Bookhout, C. G., Monroe, R. (1960). The effect of salinity and temperature on larval development of Sesarma cinereum (Bosc) reared in the laboratory. Biol. Bull. mar. biol. Lab., Woods Hole 118: 183-202

Costlow, J. D., Bookhout, C. G., Monroe, R. J. (1966). Studies on the larval development of the crab, Rhithropanopeus harrisii (Gould). I. The effect of salinity and temperature on larval development. Physiol, Zool. 39: 81-100

Díaz, H., Ewald, J. J. (1968). A comparison of the larval development of Metasesarma rubripes (Rathbun) and Sesarma ricordi H. Milne Edwards (Brachyura, Grapsidae) reared under similar laboratoy conditions. Crustaceana, Suppl. 2: 225-248

Forward, R. B. (1977). Occurrence of a shadow response among brachyuran larvae. Mar. Biol. 39: 331-341

Foskett, J. K. (1977). Osmoregulation in the larvae and adults of the grapsid crab Sesarma reticulatum Say. Biol. Bull. mar. biol. Lab. Woods Hole 153: 505-526

Fransozo, A., Negreiros-Fransozo, M. L. (1986). Influência da salinidade no desenvolvimento larval de Eriphia gonagra (Fabricius, 1781) e Sesama (Holometopus) rectum Randall, 1840 (Crustacea, Decapoda), em laboratório. Rev. Brasil. Biol. 46: $439-446$

Gerlach, S. A. (1958). Die Mangroveregion tropischer Küsten als Lebensraum. Z. Morph. Ökol. Tiere 46: 636-730

This article was submitted to the editor
Hartnoll, R. G. (1964). The freshwater grapsid crabs of Jamaica. Proc. Linn. Soc. Lond. 175: 145-169

Hartnoll, R. G. (1965). Notes on the marine grapsid crabs of Jamaica. Proc. Linn. Soc. Lond. 176: 113-147

Lam, S. C. (1969). Abbreviated development of non-marine crab, Sesarma (Geosesarma) perracae (Brachyura; Grapsidae), from Singapore. J. Zool., Lond. 158: 357-370

Lucas, J. S. (1980). Spider crabs of the family Hymenosomatidae (Custacea; Brachyura) with particular reference to Australian species: systematics and biology. Rec. Aust. Mus. 33: 148-247

McWilliams, E. L. (1969). Crabs belonging to the genus Sesarma found living in four species of bromeliads. Bromeliad Soc. Bull., Los Angeles 19: 80-82, 3 pls.

Melo, G. A. S. (1984). Taxonomia, padróes distribucionais e ecologia dos Brachyura (Crustacea, Decapoda) do litoral sudeste do Brasil. Ph.D. thesis, Instituto de Biociências, Universidade de São Paulo, Brazil

Powers, L. W., Bliss, D. E. (1983). Terrestrial adaptations. In: Vernberg, F. J., Vermberg, W B. (eds.) The biology of Crustacea, 8. Environmental adaptations. Academic Press, Inc., Orlando, p. 271-333

Rabalais, N. N., Gore, R. H. (1985). Abbreviated development in decapods. In: Wenner, A. M. (ed.) Larval growth. A. A. Balkema, Rotterdam, p. 67-126

Sachs, L. (1984). Angewandte Statistik, 6th edn. Springer Verlag, Berlin

Sattler, C., Sattler, W. (1965), Decapode Krebse als Bewohner von Bromelien.'Zisternen'. Natur. Mus., Frankf. 95: 411-415

Manuscript first received: October 4, 1989

Revised version accepted: January 19, 1990 